\title{
TWSME in Cu-Al-Ni Alloys Obtained by Stabilised Stress Induced Martensite
}

\author{
M. Gigla, J. Lelątko and H. Morawiec \\ University of Silesia, Institute of Physics and Chemistry of Metals, Katowice, Poland.
}

\begin{abstract}
The effect of deformation degree, temperature and time of ageing on the TWSME has been studied in polycrystalline and single-crystalline $\mathrm{Cu}-\mathrm{Al}-\mathrm{Ni}$ alloys. The results confirm that to obtain the best TWSME one needs to select the training parameters. The trained single crystals exhibit a lower TWSME than the polycrystalline alloys for the same training conditions. In the trained single crystals a single martensite variant has not been observed, but they showed a fewer variants than the untrained samples. The TEM studies of the trained samples exhibit a complex dislocation arrangements which interact with very thin induced plates of martensite. Ageing of the one of polycrystalline alloys caused precipitation of coherent $\gamma_{2}$ - phase particles. No precipitates were found in the second one and in the similarly trained single crystals although in these alloys a significant TWSME was observed. This means that the role of the $\gamma_{2}$ - phase particles presence to obtain the TWSME by ageing under stress is not that important as it has been suggested.
\end{abstract}

\section{INTRODUCTION}

The two-way shape memory (TWSM) effect is a well known phenomenon which can be introduced into shape memory alloys by several methods i.e. thermomechanical training [1], constraint ageing [2] or stabilisation of stress-induced martensite [3,4]. Different mechanisms of inducing the two-way shape memory effect have been suggested. Significant role is thought to be played by specific dislocation arrangements $[5,6]$, stabilised martensite plates [4], precipitates of the $\gamma_{2}$ phase $[4,7]$ and by internal stress fields $[2,4]$. Thus the problem is not solved.

The aim of this work was to study of the TWSM induced by ageing under stress in $\mathrm{Cu}-\mathrm{Al}-\mathrm{Ni}$ alloys.

\section{EXPERIMENTAL PROCEDURE}

Two polycrystalline $\mathrm{Cu}-\mathrm{Al}-\mathrm{Ni}-\mathrm{Ti}-\mathrm{B}$ alloys (P1 and $\mathrm{P} 2$ samples) and a $\mathrm{Cu}-\mathrm{Al}-\mathrm{Ni}$ single crystal ( $\mathrm{S}$ sample) were studied in the work. The characteristics of the alloys are given in Table 1 (The characteristic temperatures were determined from TWSM histeresis loops obtained by heating and cooling without external stress. TWSM effect was induced in the samples by classic thermomechanical training).

Table 1 The characteristic temperatures $\left[{ }^{\circ} \mathrm{C}\right]$ and chemical compositions of samples [wt.\%]

\begin{tabular}{|c||c|c|c|c|c|c|c|c||}
\hline sample & $\mathrm{M}_{\mathrm{s}}$ & $\mathrm{M}_{\mathrm{f}}$ & $\mathrm{A}_{\mathrm{s}}$ & $\mathrm{A}_{\mathrm{f}}$ & $\mathrm{Al}$ & $\mathrm{Ni}$ & $\mathrm{Ti}$ & $\mathrm{B}$ \\
\hline $\mathrm{P} 1$ & 25 & -12 & 5 & 40 & 13.5 & 3.2 & 0.30 & 0.07 \\
\hline $\mathrm{P} 2$ & 73 & 40 & 54 & 84 & 13.4 & 3.1 & 0.25 & 0.06 \\
\hline $\mathrm{S}$ & 128 & 87 & 115 & 153 & 13.3 & 3.0 & - & - \\
\hline
\end{tabular}


The P1 and P2 alloys were prepared in an induction furnace in argon atmosphere, then they were homogenised at $800^{\circ} \mathrm{C}$ for $1 \mathrm{~h}$ followed by hot rolling to the thickness of $0.8 \mathrm{~mm}$. The $\mathrm{S}$ specimen was grown by the Bridgman's method. Flat specimens were cut from all the three alloys, the dimensions for the $P 1$ and $P 2$ specimens were $25 \times 5 \times 0.8 \mathrm{~mm}$ and for the $S$ sample $-15 \times 4 \times 0.6 \mathrm{~mm}$. These specimens were quenched from $850^{\circ} \mathrm{C}$ to water. Then they were aged under tensile stress for different values of the deformation ( $1 \%$ or $2 \%$ ), ageing times (from 10 to 120 minutes) and temperatures (from 120 to $220^{\circ} \mathrm{C}$ ). The specimens were cooled down under the stress and then the stress was released and the specimens were 10 times cycled between $M_{f}$ and $A_{f}$.

The two-way shape memory effect was measured and calculated from the relation:

where: $\quad \Delta \mathrm{l}_{\mathbb{N D}}$ - change of the specimen length caused by the external stress during inducing

$$
\% \text { TWSM }=\frac{\Delta \mathrm{l}_{\mathrm{TWSM}}}{\Delta \mathrm{l}_{\mathrm{IND}}} \cdot 100 \%
$$

the two-way shape memory effect,

$\Delta \mathrm{l}_{\text {TWSM }}$ - change of the specimen length during a working cycle of the TWSM effect i.e.

between the $A_{f}$ and $M_{f}$ temperatures.

The structural studies were carried out on thin foils using JEM 3010 transmission electron microscope. Also light microscopy observations were conducted.

\section{EXPERIMENTAL RESULTS AND DISCUSSION}

Results of the two-way shape memory effect measurements are presented in the Table 2 . It can be seen that the defined earlier \%TWSM depends mainly on the deformation degree during the stress inducing process (Fig. 1). The average values of the TWSM effect for $2 \%$ deformation are in the range of $30-40 \%$ for both $P 1$ and P2 specimens. For $1 \%$ deformation the TWSM effect values are in the range of $60-70 \%$ which is twice as much as for the larger deformation degree. In the applied range of ageing temperatures no significant dependence of the obtained effect values on the time and temperatures of ageing was observed. This is in good agreement with the results presented in [4] for the temperatures above $100^{\circ} \mathrm{C}$.

Table 2 Values of \%TWSM obtained for different alloys and different treatment $\left(\mathrm{T}_{\mathrm{A}}\right.$ - temperature of ageing, $\mathrm{t}_{\mathrm{A}}$ - time of ageing, the notation e.g. 120/1 means that the specimen was aged at $120^{\circ} \mathrm{C}$ under $1 \%$ tensile strain)

\begin{tabular}{|c|c|c|c|c|c|c|c|c|c|}
\hline Alloy & \multicolumn{4}{|c|}{$\mathbf{P} 2$} & \multicolumn{3}{|c|}{ P1 } & \multicolumn{2}{|c|}{$\mathbf{S}$} \\
\hline Sample & $120 / 1$ & $120 / 2$ & $160 / 1$ & $160 / 2$ & $120 / 2$ & $160 / 2$ & $200 / 2$ & $185 / 1$ & $220 / 1$ \\
\hline$T_{A}-A_{f}$ & $36^{\circ} \mathrm{C}$ & $36^{\circ} \mathrm{C}$ & $76^{\circ} \mathrm{C}$ & $76^{\circ} \mathrm{C}$ & $80^{\circ} \mathrm{C}$ & $120^{\circ} \mathrm{C}$ & $160^{\circ} \mathrm{C}$ & $32^{\circ} \mathrm{C}$ & $67^{\circ} \mathrm{C}$ \\
\hline$t_{A}=10$ & 44 & 28 & 60 & $4 \overline{40}$ & & & & & \\
\hline$t_{A}=20$ & 60 & 32 & 55 & 36 & 43 & 40 & 46 & & \\
\hline$t_{A}=30$ & 64 & 30 & 61 & 40 & & & & 47 & 50 \\
\hline$t_{A}=45$ & 58 & 30 & 70 & 41 & 32 & 32 & 30 & & \\
\hline$t_{A}=60$ & 60 & 36 & 62 & 30 & & & & & \\
\hline$t_{A}=120$ & 64 & 28 & 70 & 22 & & & & & \\
\hline
\end{tabular}

The single crystal specimen which was also deformed by $1 \%$ shows values of the induced TWSM effect significantly smaller than the P1 alloy with the same deformation degree.

Light microscopy observations show (Fig. 2) that the martensite plates which were initially randomly distributed in the sample, after the TWSM training (by SSIM method) becomes partially replaced by plates of a preferential orientation in relation to the external stress direction. Both, the coagulation and reorientation of the plates were observed. However, it was not possible to obtain a single variant of the martensite plate. 


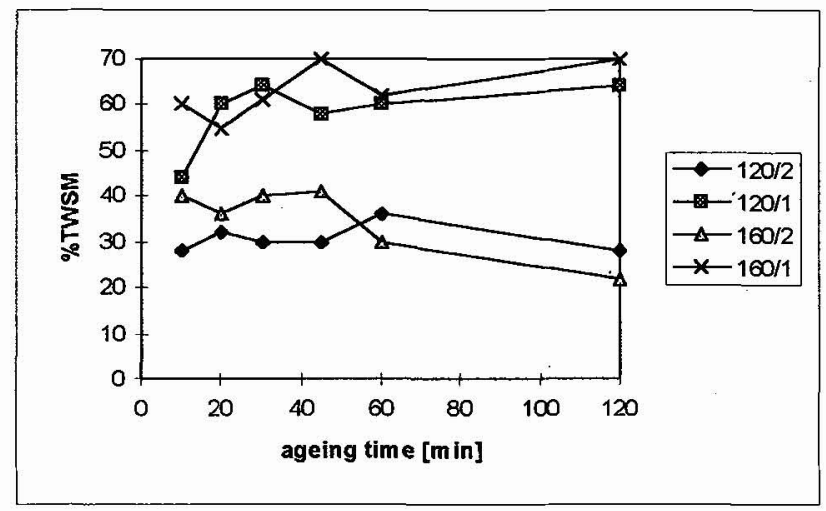

Figure 1: Values of the TWSM versus ageing time for different ageing temperatures and deformation degrees (sample P2)
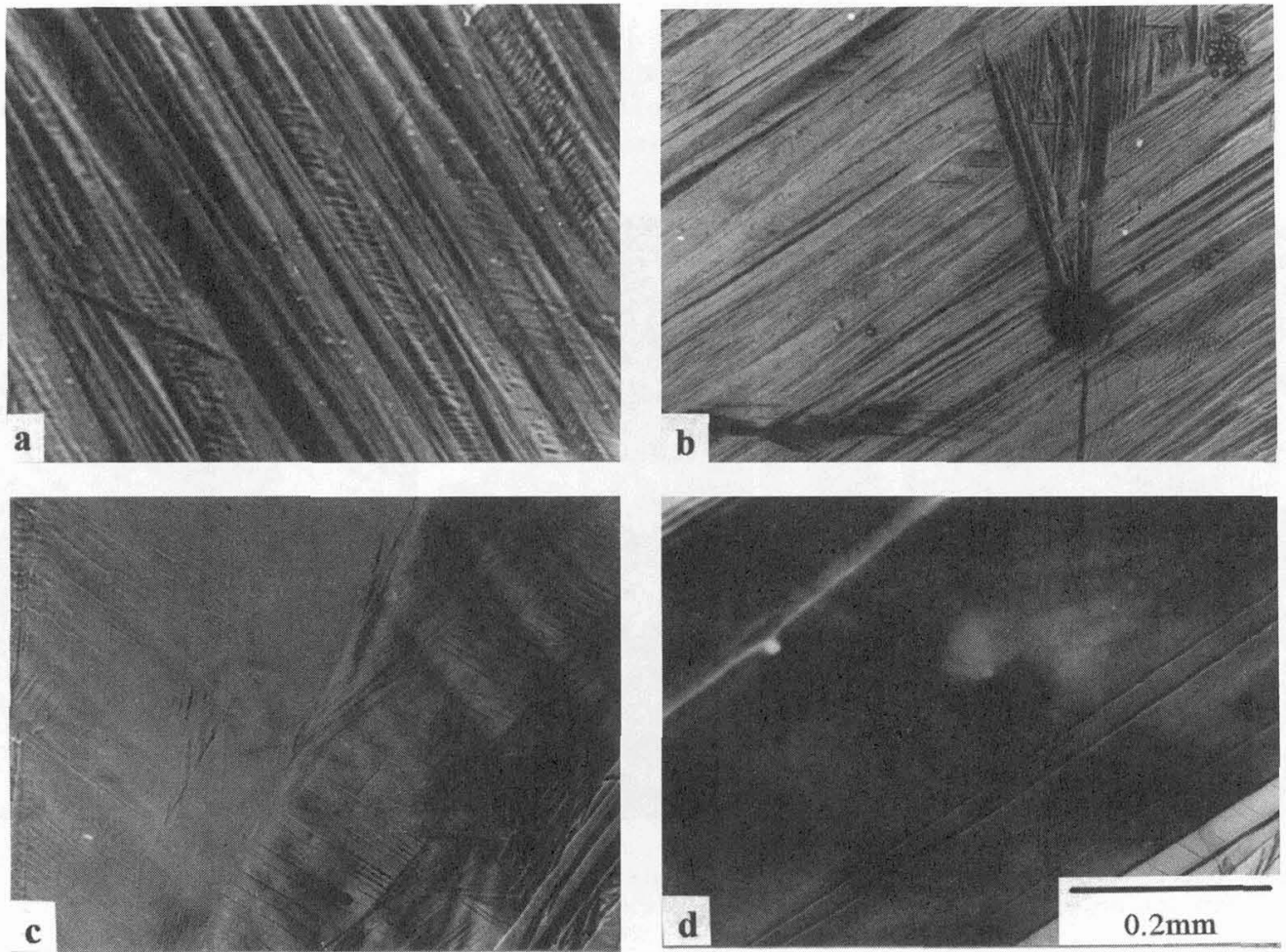

Figure 2: Microstructure of the S sample in the as-quenched state (a) (b) and corresponding images after inducing TWSM by the SSIM method (220/1) (c) and (d)

At room temperature the $\mathbf{P 1}$ alloy after inducing TWSM consisted of two phases: $\beta_{1}$ matrix and $2 \mathrm{H}$ martensite plates as it was shown by transmission electron microscopy studies. In the parent phase a complex arrangements of dislocation were observed in the form of low angle boundaries or pile-ups lying along martensite plate traces (Fig. 3). In the case of the P1 alloy small precipitates of the $\gamma_{2}$ phase were also present. 

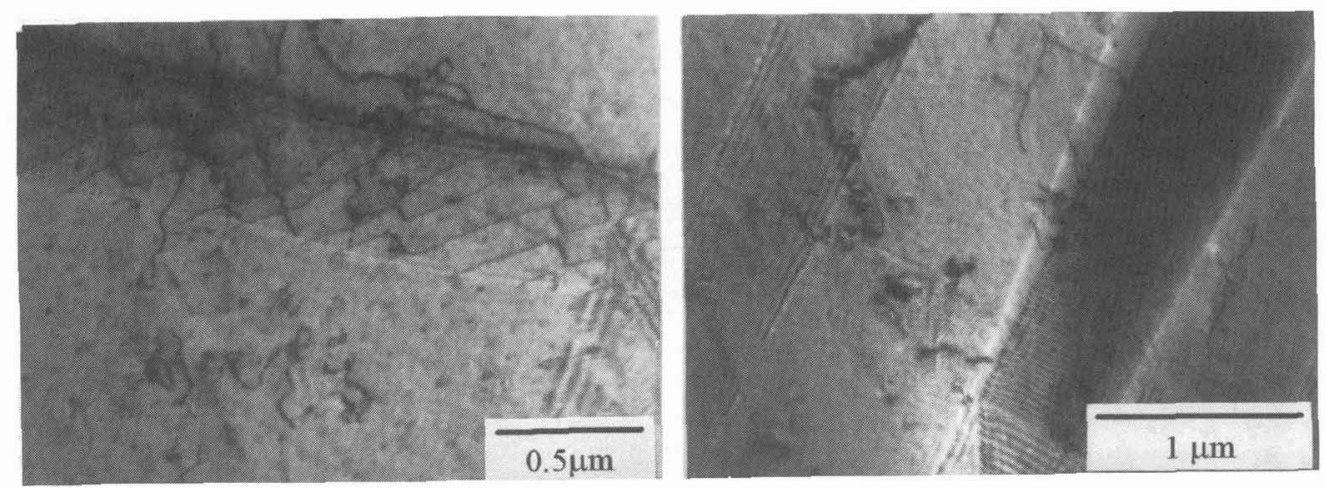

Figure 3: Structure of the $\beta_{1}$ phase in the P1 alloy after inducing the TWSM effect $\left(200 / 2, t_{A}=20\right)$

In the $\mathbf{P} 2$ alloy after inducing TWSM the $2 \mathrm{H}$ martensite was observed. In this alloy the $\gamma_{2}$ precipitates were not observed. The internal structure of the martensite plates is very complex (Fig. 4). Areas were found where inside every second plate, small plates situated at $40^{\circ}$ angle to the plate edge were visible. Inside the small plates one can see dislocations. Similar variants of the martensite plates induced inside the big original plates during the thermomechanical cycling were reported in [8].
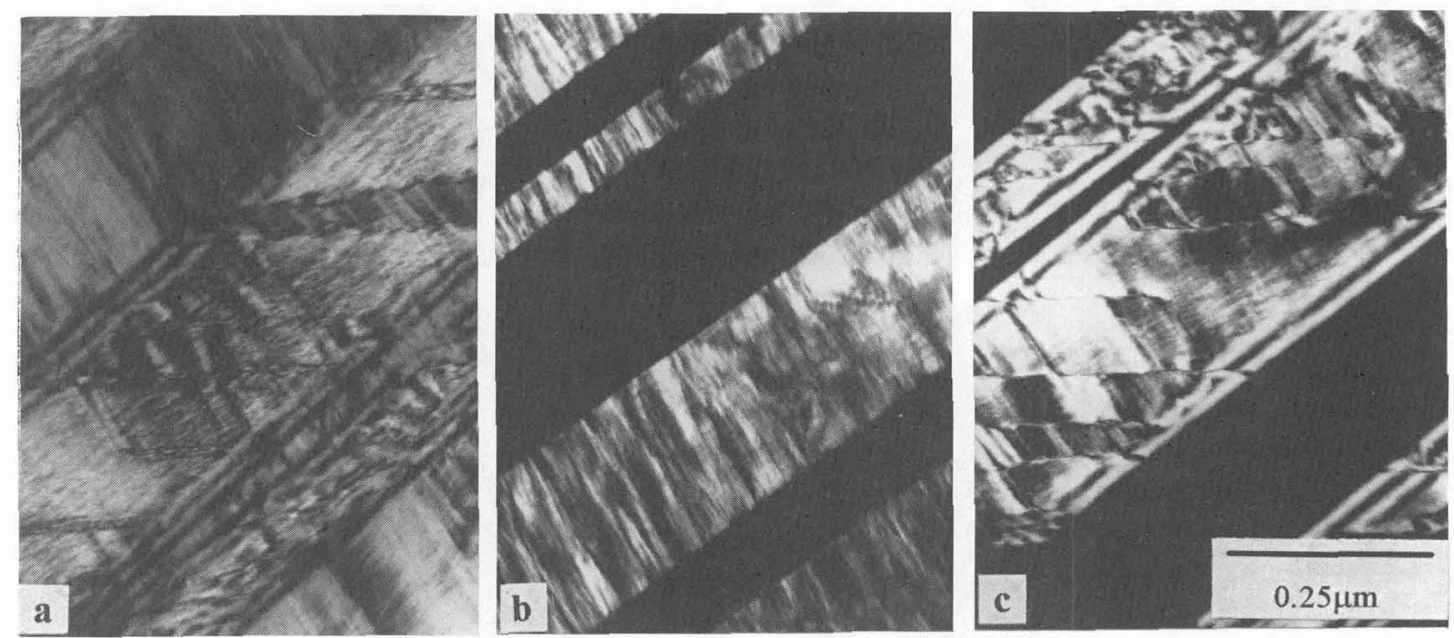

Figure 4: Structure of the P2 alloy after inducing the TWSM effect $\left(160 / 2, t_{A}=30\right)$ : bright field image (a), dark field images for two variants of martensite plates $(b)$ and $(c)$

Similar complex arrangements of tiny plates and dislocations were observed in the single crystal S sample (Fig. 5).

The specimen $\mathrm{S}$ was heated in the microscope to the temperature about $200^{\circ} \mathrm{C}$ and ,in situ" observations of the foil were carried out. It was found that the small plates inside the bigger one disappeared and in these places pile-ups of dislocations occurred (Fig. 5b). Similarly as in the P2 alloy the $\gamma_{2}$ precipitates were not observed in the $S$ sample. The difference of the internal structure of every second martensite plate observed in the $P 2$ and $S$ samples could be interpreted as the effect of different orientation of the plates in relation to the direction of the external stress. After, in situ" heating in the studied areas of the $\mathbf{S}$ sample the stabilised martensite plates were not observed, although the temperature of $200^{\circ} \mathrm{C}$ is lower than the temperature at which the TWSM effect was induced by stress. One can suggest that the applied training caused occurring 
dislocation arrangements in the parent phase which favour creation of very small martensite plates between every two parallel dislocations (Fig. 4a). The stress field arising around such plates control nucleation of the neighbouring plates. An interesting effect visible on Fig. $5 b$ is a strain-field contrast which differs from the one shown in [4]. In the samples of the $P 2$ and $S$ alloys the $\gamma_{2}$ phase precipitates were not observed, but yet the obtained two-way shape memory effect is large. This means that the precipitates do not play that important role in inducing the effect by ageing under stress as it was suggested in $[4,7]$.
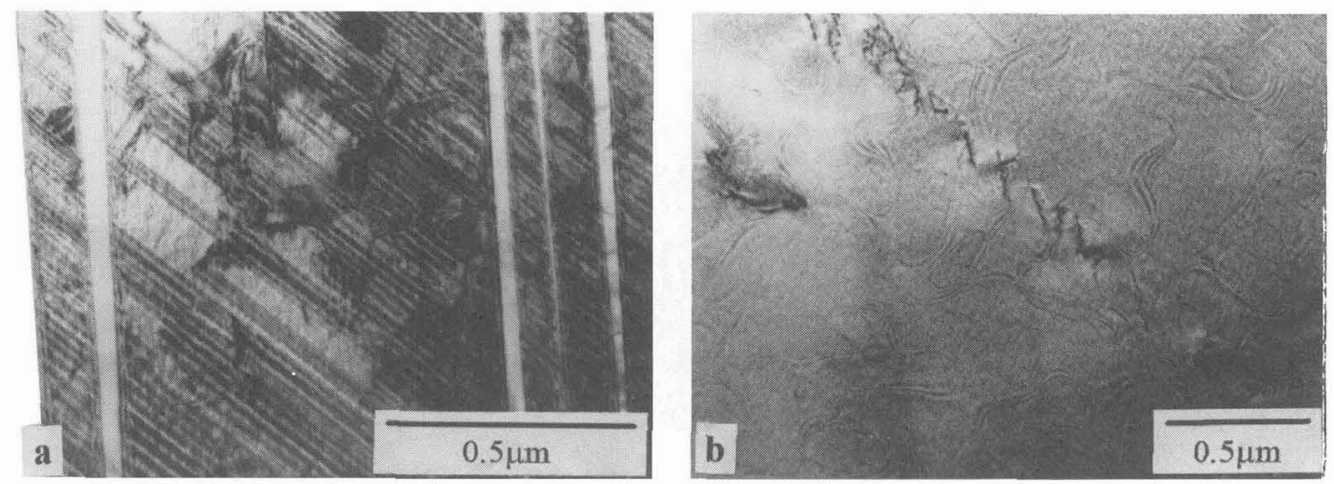

Figure 5: Structure of the 220/1 sample of the S alloy after inducing the TWSM effect (a) and after ,in situ" heating (b)

\section{CONCLUSIONS}

- The value of a deformation degree applied during inducing the TWSM effect by the SSIM method has the biggest influence on the \% TWSM value.

- No important influence of the $\gamma_{2}$ precipitates on the value of the TWSM effect induced by the SSIM method was observed in the studied alloys.

- A complex internal defect structure depending on the variant of the martensite plates was observed which could be due to different (more or less favourable) orientation of the plates in relation to the external stress during inducing.

- The observed dislocation arrangements and related fine plates of the martensite create stress fields which are responsible for the TWSM effect.

\section{Acknowledgements}

The JEM3010 transmission electron microscope was presented to the Institute of Physics and Chemistry of Metals, University of Silesia by the Polish Foundation for Science.

This work was sponsored by the National Committee of Research through project No 7TO8A05108.

\section{References}

[1] J. Perkins, R.O. Sponholtz, Met. Trans., 15A (1984) 313

[2] R. Jean, H.J. Lai, S.C. Cheuh, Proc. Int. Conf. on Martensitic Transformations, Monterey (1992) 1119

[3] R. Rapacioli, V. Torra, E. Cesari, J.M. Guilemany, J.R. Miguel, Scripta Metall., 22 (1988) 261

[4] J.M. Guilemany, J. Fernandez, J. de Physique IV, C2 (1995) C2-355

[5] M.Sade, A. Uribarri, F.C. Lovey, Phil. Mag A,55 (1987) 455

[6] F.C. Lovey, P.L. Rodriguez, J. Malarria, M. Sade, V. Torra, J. de Physique IV, C2 (1995) C2-287

[7] A. Amengual, E. Cesari, J. Pons, J. de Physique $I V$, C8 (1995) C8-871

[8] M. Qi, C.Y. Chung, D.Z. Yang, J. de Physique IV, C8 (1995) C8-931 